\title{
Problems and Countermeasures of Social Work Talent Cultivation in Youth Affairs
}

\author{
Zhang Heng \\ School of Innovation and Entrepreneurship, Xi’an Fanyi University, Shaanxi, China, 710105
}

Keywords: youth affaires; social work; talent cultivation

\begin{abstract}
This paper conducts in-depth research and understanding of the current situation of social work talents for youth affairs, researches and analyzes the status quo and existing problems in the construction of youth affairs and social work talents. Through the analysis of research conditions, the use of relevant theories and external experience, combined with actual work, on the basis of key points from the study of public affairs management and human resources management, countermeasures and suggestions are put forward. This paper proposes that it should actively change government functions, make overall plans for science, strengthen cognitive propaganda, build and play the role of industry associations, and accelerate the construction of a new type of work structure, and strengthen job setup, increase training efforts, improve assessment and evaluation, and open channels for development.
\end{abstract}

\section{Introduction}

Social work for youth affairs is an important practical field for social work. It is to use young people as the target of service. Based on the physiological characteristics, cognitive patterns and development needs of young people, professional methods and techniques of social work are used to stimulate the potential of young people, promote the comprehensive development of young people and help them adapt to the professional activities of the society. At present, social work for youth affairs can be divided into three areas according to the target orientation, as showed below in Table 1 .

Table1. Typical areas of youth affaires

\begin{tabular}{cc}
\hline No. & Areas \\
\hline 1 & Serving the growth and development of young people \\
3 & Protecting the legitimate rights and interests of young people \\
\hline
\end{tabular}

The team of social workers in youth affairs is a professional talent engaged in community youth work, serving grassroots community development, and promoting social governance innovation, and it is an important part of the social worker talent system. In order to do well in youth work, it should be build a strong social workforce for young people.

\section{Status Quo and Problems of Social Work Talents in Youth Affairs}

At present, the construction of youth social work and professional talents in China is still at the initial stage, which is far from meeting the requirements of social work for adolescents. It is mainly manifested in the following aspects.

\subsection{The small overall scale failing to meet the realistic needs}

As a result of the late start of professional social work in China, although a large number of people have been engaged in "practical social work" in fact, their professionalism and professionalism have not been sufficiently developed and paid attention to. Until July 2004, the social work was officially identified as a new occupation in China. Although the function of youth work has always been included in the traditional grass-roots community work, there has never been a professional team 
specializing in teenagers' specific affairs. The more and more prominent youth social problems are urgently needed by professional and professional staff to face and solve them. However, because of the low development time, the size of the professional personnel of social workers in the youth affairs of our country is still relatively small. By 2015, there are only 20 thousand professional social workers in the National Youth Affairs, which is equivalent to only 5.3 youth for every 100 thousand young people. Juvenile social work practitioners cannot meet the realistic needs of youth affairs, and are far from fine services.

\subsection{Unbalanced distribution}

As the Communist Youth League organizations shoulder the social functions of serving young people and developing youth affairs, the national social workers for youth affairs are mainly concentrated in youth service organizations and institutions initiated and promoted by the Communist Youth League. These organizations and institutions include 12355 youth help desks, youth palaces, youth volunteer associations, juvenile justice institutions, youth centers, community youth exchanges, and youth homes. These organizations and organizations usually set up youth social work professional posts based on the characteristics and needs of the clients and the degree of difficulty in carrying out work, and they are equipped with social workers for youth affairs with different job levels and number of posts. However, in a large number of primary and secondary schools and geographically vast urban and rural communities, there are only a handful of social workers for youth affairs, which are far from meeting the demand.

At the same time, although the construction of social workers for youth affairs in China has been significantly accelerated in recent years, the level of development in various provinces and cities has been uneven, and the situation of social worker recruitment for youth affairs is also very uneven. In some cities like Beijing and Shanghai, and developed regions in the South, the staffing rate of social workers for youth affairs is significantly higher than that of other regions.

\subsection{Lack of specialization}

Although China's youth social work professional talents have embarked on a professional and professional path, due to various reasons, the current high level of specialization of youth social work professionals is obviously insufficient. The lack of professional training, the problem of less professional qualifications is more prominent.

\subsection{Insufficient practical capacity}

The problems and demands faced by adolescent groups have strong commonalities, and also have significant differences in personality. People who have certain work and life experiences can understand and grasp them, and on this basis, they can provide effective services and help. Affected by various reasons such as salary, career development, working conditions, and social assessment, experienced and enthusiastic people in society have not joined this team. As a result, the overall age of social workers in youth affairs is light and the relevant work is lacking life experience and social experience. In addition, many youth social workers are not adequately trained, lack understanding of relevant knowledge, and are unaware of relevant policies and regulations. They are unable to meet the practical requirements of young people's services and often feel uncomfortable in the face of numerous youth affairs.

\section{Main Factors Affecting the Cultivation of Social Work Talents in Youth Affairs}

\subsection{Career orientation and development}

As a profession, youth social work is bound to have career orientation and career planning. However, due to various reasons, the current social orientation and development of youth social work is not clear enough. First of all, the whole society does not attach enough importance to youth social work, and lacks top-level design for the construction of youth social work talents team. Secondly, young people's social institutions, grass-roots communities and other employing units and 
departments lack vocational training for young social workers. Finally, social workers for youth affairs themselves have not grasped the work they are engaged in from the point of view of career development and have not positioned themselves from the perspective of career planning. A large proportion of social workers in youth affairs choose the current job, just out of expediency. They often use current work as a springboard or a transition. Unclear career positioning, misunderstanding and chaos of role recognition have also led to confusion in their work and prospects.

\subsection{Remuneration level}

Reasonable income is an important factor to promote the stability and development of employees in an industry, and is also an important guarantee for safeguarding occupational safety. Long term low income operation leads to the attraction of youth social work profession is not strong enough to retain talents.

\subsection{Degree of specialization and professionalism}

At present, China's colleges and universities do not set up youth social work majors, and do not include young social workers in the professional talent team training system. Most social workers in youth affairs have not received systematic professional education or formal professional training, and it is difficult to provide systematic, diversified and personalized services. They are also unable to effectively face the endless new situations, new contradictions and new problems.

\subsection{Social recognition}

Many aspects of youth social affairs are "soft" services, such as young people's social education, social participation, social security, rights and interests maintenance, cultural entertainment, social communication and other services. These social affairs are more focused on safeguarding the physical and mental health of young people, which is subtle and the service effect is also implicit. These are often not fully valued by the whole society and all families. The social work of youth affairs has not been widely recognized by the whole society.

\section{Countermeasures for the Training of Social Work Talents in Youth Affairs}

Strengthening the building of social workforce for youth affairs is a systematic project. It must adhere to the problem-oriented approach, meet the needs of young people in social affairs, improve the level of social services, adhere to the path of specialization and professionalism, and provide scientifically sound social services for young people.

\subsection{Strengthen professional and vocational training of social work talents in youth affairs}

First of all, the education of social workers for youth affairs should be included in the higher vocational education system, and tertiary institutions should be encouraged to set up professional courses for youth social work and improve the relevant theoretical research and training systems so as to protect the professionalism of youth social work professionals.

Secondly, it should attach great importance to and actively promote the on-the-job training of social workers for youth affairs, relying on colleges and universities, youth social organizations, social work organizations, and focusing on social surveys, social policy applications, psychological counseling, and youth activity organizations, with plans and levels. On-the-job training of social workers for youth affairs is carried out to effectively enhance the practical capabilities of the group.

\subsection{Improve youth social work talents protection and career development mechanism}

It should improve the professional salary system for social workers in youth affairs. It is necessary to establish social work talents for youth affairs to guide the salary standards and improve the wage growth mechanism so as to ensure that the salary level of social work personnel for youth affairs is consistent with the level of national economic growth. The second is to establish a salary incentive mechanism for social workers for youth affairs. The third is to establish a career promotion mechanism. And to guide and encourage talented young social workers to apply for professional titles, 
and to tie job titles to wage levels.

\subsection{Enhance publicity and the recognition of social work talents in youth affairs}

One of the major problems encountered in the development of social work teams for youth affairs is the low social recognition and low influence of social workers in youth affairs. The work and commitment of social work for youth social workers has not been effectively affirmed. Social work for young people in social affairs is lacking in recognition of their own occupations. There is not enough confidence in the future. Therefore, while improving the work and professional abilities of social workers for youth affairs, it is necessary to strengthen the cultivation of the moral qualities of young social workers, help them improve their professional confidence, and guide them to believe that engaging in youth affairs is necessary for social development and progress. It is a matter for young people. For development, the work of social workers for youth affairs can meet the concerns of society and meet the development of youth affairs.

\section{Conclusion}

Based on the basic theories, concept elements, and research status of the construction of the social work talents for youth affairs, the basic concepts and research priorities of the research subjects are clearly defined. It can be seen that the youth social work professional talents still have problems such as low professionalism, imperfect management mechanisms, weak private operation skills, and insufficient social awareness. The construction of social work teams for youth affairs is a long-term and complicated system project. It is necessary to inspect the relevant factors more thoroughly, comprehensively, and historically. At the same time, it is also the main direction of the next work to combine and match the characteristics and interest demands of the youth group and improve the practical value of the research results.

\section{Acknowledgement}

Current situation and Development of Education for Social work Specialty (Youth Affairs) in Shaanxi Colleges and Universities in 2014 (Project No.: 2014SYQY17) The Research Project of Education and Teaching Reform of Xi'an Translation Institute in 2015 (emphasis) < Research on Educational and Teaching Development of Social work Specialty (Youth Affairs) in our College "(item No.: J15A07)

\section{References}

[1] Wen Jun. International comparative study of community youth social work [M]. Shanghai: East China University of Technology Press, 2012.

[2] Wang Yuxiang. Youth Social Work [M]. Jinan: Shandong People's Publishing House, 2012.

[3] Zhang Youde. Youth Social Work [M]. Tianjin: Tianjin University Press, 2010.

[4] Fang Ying. The current situation, causes and countermeasures of the social mobility of young social workers [J]. Youth Exploration, 2015, (3)

[5] Ma Zhiqiang. A new theory on the positioning of social work in China [J]. Zhongzhou Academic Journal, 2017, (2). 